\title{
A Prática de Ensino como Rito de Passagem e o Ensino de Sociologia nas Escolas de Nível MÉdio
}

\author{
Anita Handfas ${ }^{1}$ \\ Rosana da Câmara Teixeira ${ }^{2}$
}

\begin{abstract}
Resumo
0 objetivo do artigo é discutir algumas questões relacionadas à formação inicial do professor e ao ensino de Sociologia no ensino médio. As questões trazidas têm origem na concepção de Prática de Ensino como rito de passagem, favorecendo as condições para uma formação que leve em conta as variadas dimensões do processo escolar. Na primeira parte, o artigo apresenta o conteúdo teórico e prático do curso de Didática Especial e Prática de Ensino de Ciências Sociais da UFRJ para em seguida problematizar algumas questões referentes ao ensino de Sociologia no nível médio.

Palavras-Chave: Prática de Ensino. Formação do professor. Sociologia no ensino médio.
\end{abstract}

\begin{abstract}
This paper discusses some subjects related to the teacher's initial formation and to the Sociology teaching in the secondary level. The subjects have origin in the conception of Practice of Teaching as ritual of passage, favoring the conditions for a formation that considers the varied dimensions of the school process. In the first part, the paper presents the theoretical and practical content of the course of Special Didacticism and Practice of Teaching of Social Sciences of UFRJ and finally it problematizes some subjects about the Sociology teaching in the medium level.

Key-words: Practice of Teaching. Teacher's formation. Sociology teaching in the secondary.

\section{INTRODUÇÃO}

$\mathrm{N}$

este artigo buscamos sistematizar a experiência de dois anos durante os quais compartilhamos nosso trabalho como professoras de Didática Especial e da Prática de Ensino de Ciências Sociais, do curso de licenciatura da Faculdade de Educação da UFRJ. Seu objetivo é levantar alguns elementos vivenciados empiricamente, tanto nas

\footnotetext{
${ }^{1}$ Mestre em Educação pela UFRJ. Doutora em Educação pela UFF. Professora assistente da Faculdade de Educação da Universidade Federal do Rio de Janeiro. Email: ahandfas.bol@uol.com.br.

${ }^{2}$ Mestre em Sociologia pelo PPGSA/UFRJ. Doutora em Antropologia Cultural pelo PPGSA/UFRJ. Professora da UNILASALLE/RJ e na Faculdade de Educação da UERJ. Email: rosanadacamara@oi.com.br.
} 
discussões com os alunos em sala de aula, como também nas atividades da Prática de Ensino, incluindo o estágio supervisionado realizado nas escolas de ensino médio da rede pública federal e estadual. Dessa forma, pretendemos contribuir com o debate em torno da formação do professor de Sociologia, cuja relevância é incontestável, sobretudo no momento em que esta disciplina, ao menos do ponto de vista legal, adquire o status de disciplina obrigatória em todas as escolas brasileiras de nível médio ${ }^{3}$.

Váriossão os aspectos que consideramos relevantes no que diz respeito à relação entre a Prática de Ensino e a formação inicial do professor, contudo, neste artigo, nosso foco estará voltado para a reflexão sobre: a) a Prática de Ensino como momento privilegiado na formação inicial do professor; e b) o ensino de Sociologia para os alunos do nível médio.

Com efeito, as questões apontadas para a discussão derivam, em parte de concepções teóricas que orientaram a formulação do conteúdo programático do curso, e, por outro, da sua articulação com o contexto de estágio, com vistas a conjugar formação teórica e prática educativa, "para que não se perca a visão de totalidade da prática pedagógica e da formação como forma de eliminar distorções decorrentes da priorização de um dos pólos" (CANDAU, 2003, p. 69).

A seguir passaremos a expor os pressupostos a partir dos quais desenvolvemos 0 curso, tecendo algumas considerações sobre a Prática de Ensino ${ }^{4}$.

\section{O CONTEÚdO PROGRAMÁTICO DO CURSO: a Prática de Ensino como rito de Passagem}

Do ponto de vista conceitual, partimos da compreensão de que a formação do professor deve contemplar o processo escolar como uma totalidade complexa e repleta de contradições. Rejeita-se aqui tanto a idéia de que a formação inicial do professor seja meramente técnica quanto a idéia de que constitui-se em um ato espontâneo ou improvisado. Ao contrário, reafirma-se a concepção de que aformação e a prática pedagógica devem englobar a dimensão do trabalho educacional e científico do professor, o que implica refletir sobre as questões referentes ao ensino da Sociologia no ensino médio, tendo como foco a escola - ambiente complexo e multifacetado - e a interação entre seus agentes em seus variados matizes.

\footnotetext{
${ }^{3}$ No estado do Rio de Janeiro, a Sociologia já é uma disciplina constante do currículo das escolas de ensino médio desde 1989. Não obstante, acreditamos que o recente parecer n 38/2006 do Conselho Nacional de Educação, de 07 de julho de 2006, dispondo sobre a sua inclusão obrigatória como componente curricular do ensino médio em todo o território nacional, deverá dar um novo impulso às discussões sobre a prática de ensino desta disciplina para jovens do ensino médio.

${ }^{4}$ A licenciatura da Faculdade de Educação da UFRJ é composta por um conjunto de disciplinas pedagógicas, incluindo Didática Especial I e II, ministradas concomitantemente com a Prática de Ensino, momento em que o licenciando realiza o estágio na escola, bem como uma série de atividades relacionadas à prática do ensino de Ciências Sociais.
} 
Nessa direção, nosso trabalho tem sido conduzido basicamente a partir de três eixos de análise: a escola, a formação do professor e 0 ensino de Sociologia. Esses eixos percorrem todo o curso de forma articulada, favorecendo assim a interlocução entre as questões teóricas do curso e a prática do estágio cujo aprofundamento é favorecido pelo confronto entre a realidade vivenciada pelo aluno na escola e a reflexão teórica do processo escolar.

A possibilidade desse confronto se dá na medida em que compreendemos a Prática de Ensino como rito de passagem. Isto significa considerá-la, tal como sugere Monteiro (2002), um momento de descentração, privilegiado na constituição da profissionalidade, possibilitando reflexões sobre as atividades desenvolvidas.

Do ponto de vista antropológico, um ritual de passagem refere-se à passagem de um indivíduo de um status social a outro no decorrer da sua vida. Por mais diversos que sejam, apresentam três fases seqüenciais: separação, liminaridade, agregação. Segundo Victor Turner (1974, p.116-117):

a primeira fase (de separação) abrange o comportamento simbólico que significa 0 afastamento do indivíduo ou de um grupo, quer do ponto fixo anterior na estrutura social, quer de um conjunto de condições culturais (um "estado"), ou ainda de ambos. Durante o período "limiar" intermédio, as características do sujeito ritual (o transitante) são ambíguas; passa através de um domínio cultural que tem poucos, ou quase nenhum dos atributos do passado ou do estado futuro. Na terceira fase (reagregação ou reincorporarão), consuma-se a passagem. 0 sujeito ritual, seja ele individual ou coletivo, permanece num estado relativamente estável mais uma vez, e em virtude disto tem direitos e obrigações perante os outros de tipo claramente definido estrutural, esperando que se comporte de acordo com certas normas costumeiras e padrões éticos, que vinculam os incumbidos de uma posição social, num sistema de tais posições.

A fase de trânsito é ambígua, na qual se experimenta uma condição liminar interestrutural em que se opera uma transformação. Período reflexivo em que os neófitos são encorajados a pensar sobre sua sociedade, seu cosmos e poderes que geram e sustentam. Para Turner, entre a pessoa de antes e depois opera-se uma transformação.

Na Prática de Ensino, o licenciando vivencia uma dupla condição, a de aluno e a de professor num processo de iniciação coletiva que tem no relacionamento humano seu eixo (MONTEIRO, 2002). Nessa direção, é bastante oportuno que os licenciandos sejam da área de Ciências Sociais. Para o aluno que concluiu ou encontra-se em fase de conclusão de seu curso de graduação, este processo pode tornar-se mais atraente, na medida em que ele seja estimulado a fazer uma imersão no campo de estágio, afiando 
seu olhar antropológico para captar os inúmeros elementos presentes na dinâmica escolar que podem assim se constituir em objeto de análise.

Se por um lado, esta empreitada, em alguma medida, implica transformar 0 familiar em exótico, nos termos propostos por Roberto Da Matta $(1978)^{5}$, ou seja estranhar uma realidade que vivenciamos efaz parte de nossa trajetória - a experiência escolar -, por outro parece fundamental supor como pondera Gilberto Velho (1994) que o familiar nãoé necessariamente conhecido ${ }^{6}$. 0 fato de cada aluno ter uma experiência escolar prévia não significa que compreenda as regras que organizam aquele universo, as formas de sociabilidade que ali se estabelecem, os projetos individuais e/ou coletivos que se desenvolvem. 0 convite feito ao nosso aluno logo nas primeiras aulas é o de valendo-se do referencial das Ciências Sociais, pensar a sua entrada na escola a partir da descrição emblemática de Malinowski (1978, p.19) quando chega à aldeia nas ilhas Trobriand, no Pacífico Sul:

Imagine-se o leitor sozinho, rodeado apenas de seu equipamento, numa praia tropical próxima a uma aldeia nativa, vendo a lancha ou o barco que o trouxe afastar-se no mar até desaparecer de vista [...]. Suponhamos, além disso, que você seja apenas um principiante, sem nenhuma experiência, sem roteiro e sem ninguém que o possa auxiliar - pois o homem branco está temporariamente ausente ou, então, não se dispõe a perder tempo com você.

0 licenciando é estimulado a registrar suas impressões em um caderno de campo durante sua permanência na escola, possibilitando não apenas uma troca mais orientada com os colegas, mas a utilização desse registro na elaboração do relatório apresentado ao final do estágio e do qual se espera uma reflexão que demonstre que "esteve lá" .

Nessa direção, encontros periódicos são promovidos para que os alunos relatem suas experiências e percepções de modo a melhor dimensionarem o lugar da Sociologia no ensino médio, bem como os desafios e as possibilidades abertos à prática docente.

\footnotetext{
5 Para Da Matta (1978, p.28-29), tornar-se antropólogo implica aprender a realizar uma dupla tarefa: transformar o exótico em familiar - movimento inicial da Antropologia quando procurava-se compreender realidades sócioculturais diferentes, aquilo que "a cultura do pesquisador reveste inicialmente de bizarro" e/ou transformar o familiar em exótico, quando nos voltamos para a análise de nossa própria sociedade e torna-se então, crucial, "tirar a capa de membro de alguma classe e de um grupo social específico para poder - como etnólogo - estranhar alguma regra social familiar e assim descobrir [...] o exótico no que está petrificado dentro de nós...".

${ }^{6}$ Segundo Gilberto Velho (1994, p.126), o fato de dois indivíduos pertencerem à mesma sociedade não significa que estejam mais próximos, ou seja "o que vemos e encontramos pode ser familiar mas não necessariamente conhecido e o que não vemos e encontramos pode ser exótico mas até certo ponto conhecido. No entanto, estamos sempre pressupondo familiaridades e exotismos como fontes de conhecimento ou desconhecimento, respectivamente".

${ }^{7}$ Clifford Geertz sugere que a habilidade dos antropólogos para nos fazer levar a sério o que dizem tem menos a ver com seu caráter factual ou sua elegância conceitual e, muito mais, com sua capacidade de convencer os leitores de que realmente "estiveram lá".
} 
Pede-se que estejam atentos aos processos de ensino-aprendizagem, didáticos, materiais e recursos utilizados e formas de avaliação, buscando alternativas didáticas no sentido de estreitar a distância entre o discurso sociológico e o cotidiano desses alunos.

Um olhar atento permitirá surpreender processos sociais que perpassam o ambiente escolar, resgatando o papel ativo dos sujeitos permitindo identificar as relações sociais travadas na escola, os conflitos sociais e funcionais da escola pública, tal como analisados por Saes e Alves (2004), bem como as diferentes manifestações dos alunos das classes trabalhadoras (SAES; ALVES, 2003).

A escola, realidade socialmente construída, inserida num contexto sócio- histórico específico - a sociedade complexa, urbana -, na qual se entrecruzam trilhas sociológicas diferenciadas é entendida como espaço social próprio ordenado em dupla dimensão, como afirma Juarez Dayrell (1996, p.137):

Institucionalmente, por um conjunto de normas e regras, que buscam unificar e delimitar a ação dos sujeitos. Cotidianamente, por uma complexa trama de relações sociais entre os sujeitos envolvidos, que incluem alianças e conflitos , imposição de normas e estratégias individuais, ou coletivas, de transgressão e de acordos. Um processo de apropriação constante dos espaços, das normas, das práticas cotidianas e dos saberes que dão forma à vida escolar.

É preciso estar atento ainda à trajetória escolar e aos interesses e expectativas, muitas vezes distintos da juventude presente no espaço escolar, desconfiando de sua aparente homogeneidade. Como advertiu Bourdieu (1983, p.113) "falar dos jovens como se fosse uma unidade social, um grupo constituído, dotado de interesses comuns, e relacionar estes interesses a uma idade definida biologicamente já constitui uma manipulação evidente". Afinal, quem são estes jovens que chegam à escola? 0 que vêm buscar? Que expectativas indicam ter em relação ao ensino da sociologia? Apreender a diferença real dos alunos implica considerá-los como sujeitos sócio-culturais que possuem historicidade, visão de mundo, lógicas de comportamento próprias (DAUSTER, 1996, p.14). Não se deve pois perder de vista que a escolaé tanto um lugar de acesso a determinados conteúdos quanto um espaço de sociabilidade.

É sobre esse ambiente complexo e multifacetado que o licenciado é estimulado a mergulhar, com vistas a favorecer a compreensão de que o educador tem um papel estratégico no sentido de propiciar o diálogo e a comunicação entre os mundos diferenciados que ali se entrecruzam, num esforço permanente de entendimento das diferenças (DAUSTER, 1996, p.70).

É importante ainda estar atento às orientações pedagógicas e curriculares adotadas pelas escolas que a despeito de estarem subordinadas às diretrizes gerais estabelecidas nos 
Parâmetros Curriculares Nacionais, constituem verdadeiro palco de disputas entre diferentes concepções político-pedagógicas existentes na escola. Certamente, como afirma Lopes (2000) a prática pedagógica do professor sofre os influxos dessas disputas, ao mesmo tempo em que exerce influência sobre elas a partir da maneira com que ele se relaciona com as demais práticas na escola.

Outro elemento muito importante também examinado diz respeito à trajetória da Sociologia no ensino médio. Como se sabe, por motivações distintas, sua história como disciplina escolartem sido caracterizada ora pelasuapresença, orapela ausência nos currículos das escolas secundárias. No decorrer do curso, procura-se discutir esse processo, analisando fatores que teriam determinado tal intermitência, certamente um dos fatores responsáveis pela falta de tradição do seu ensino, dificultando a pesquisa e o desenvolvimento de metodologias adequadas. Além disso, a Sociologia não chegou a desenvolver um conjunto mínimo de conteúdos sobre os quais haja consenso. Partindo do pressuposto de que os limites da ciência Sociologia não coincidem com os da disciplina, já que não se trata de uma mera transposição de conteúdos epráticas, éfundamental discutir as formas de tradução, aos recortes propostos, enfim, como os professores de ensino médio vêm dialogando com as orientações curriculares, tanto à nível nacional, como estadual ${ }^{8}$.

Assim considerando, o estágio na escola assume uma dimensão que extrapola os limites do ensino da Sociologia, na compreensão de que o seu desenvolvimento só poderá se dar, na medida em que estejam articulados aos inúmeros elementos presentes na dinâmica escolar. Nessa perspectiva, a escola é pensada como espaço privilegiado de estágio e, a Prática de Ensino, como espaço privilegiado de formação inicial e continuada dos professores. Entendemos portanto que o curso de licenciatura pode cumprir um papel fundamental no intercâmbio entre a universidade e a escola básica. Para o sucesso dessa proposta de trabalho éfundamental a participação efetiva dos professores regentes com os quais procuramos estabelecer um diálogo permanente ${ }^{9}$.

Vale lembrar que o estágio é supervisionado pelo professor de Didática Especial (o mesmo da Prática de Ensino) com o objetivo de conjugar o estudo sobre as questões relacionadas ao ensino da sociologia às reuniões de supervisão das atividades de estágio com os licenciandos e com as equipes de professores das escolas que recebem nossos alunos para o estágio.

Tal orientação é coerente com a política de formação de professores da Faculdade de Educação da UFRJ que em seu projeto institucional afirma que:

\footnotetext{
${ }^{8}$ Ver Parâmetros Curriculares Nacionais - Sociologia. 2005 e Reorientação Curricular para o ensino médio e ensino fundamental no estado do Rio de Janeiro. Ciências Humanas. Sociologia. 2004.

${ }^{9}$ É importante destacar que no Rio de Janeiro desenha-se um cenário muito estimulante com a recente admissão de professores concursados para a disciplina.
} 
Esse profissional desempenha um papel estratégico na articulação entre o que está sendo objeto de pesquisa, ensino e discussão na universidade e as práticas pedagógicas desenvolvidas na unidade escolar. A supervisão assume, assim, o sentido de mediação entre as duas instâncias de formação, criando possibilidades para a realização de um estágio no qual teoria e prática não se separam. Além disso, essa mediação poderá suscitar iniciativas de inovação na escola, abrir canais para a expressão de suas demandas de formação continuada, possibilitando uma constante atualização do ensino e das práticas realizadas na universidade. Para o desenvolvimento desse trabalho, os professores regentes das turmas nas escolas também são convidados a participar do processo de orientação dos estagiários. em que a escola e a universidade se comprometam a trabalhar em conjunto pela formação dos professores e pela melhoria do ensino na instituição escolar. Isso implica uma abertura para o diálogo e a ação nos momentos de planejamento, execução e avaliação do trabalho como um todo (CENTRAL DE ESTÁGIO, 2004, p.9-10).

Como vimos, vários são os aspectos que o curso busca contemplar e no espaço deste artigo procuramos elencá-los sem contudo ter a pretensão de desenvolver cada um deles. A intenção principal foi a de explicitar nossa concepção sobre a formação inicial do professor de Ciências Sociais, destacando a Prática de Ensino como um rito de passagem e as possibilidades abertas por esta estratégia, especialmente no sentido de favorecer a análise teórica e prática dos processos educacionais como um todo e, em particular da escola, da formação do professor e do ensino de Sociologia.

Como já assinalado, sendo o fio condutor do curso os limites e as possibilidades do ensino de Sociologia no ensino médio, a pergunta que se coloca é: como garantir a apropriação e a socialização do conhecimento sociológico nas condições reais do processo escolar? No próximo item, nos propomos a focalizar esta questão, relacionando-a com alguns aspectos concernentes à formação de professores.

\section{O ENSINo da Sociologia nas escolas DE NÍVEL MÉDIO}

Ao considerar que a prática de ensino de Ciências Sociais deve levar em conta as variadas dimensões do processo escolar não estamos subestimando os problemas específicos do ensino, tais como a transposição dos conteúdos, o desenvolvimento de metodologias apropriadas, a elaboração de materiais didáticos, assim como as questões ligadas ao planejamento e à avaliação do ensino. Ao contrário, como procuramos demonstrar, acreditamos que todos esses aspectos ganham maior rigor e aprofundamento na medida em que sejam tratados dentro de um contexto mais amplo em que o ensino se insere.

Como afirmamos, quanto maior for o número de elementos que possamos captar 
e quanto maior a nossa capacidade de analisar a intervenção desses elementos na dinâmica do processo escolar, melhores serão as condições para examinar os problemas referentes ao ensino e elaborar proposições que possibilitem a apropriação dos conteúdos sociológicos pelos alunos do ensino médio.

Nessa perspectiva, concordarmos com Dermeval Saviani quando afirma que cabe à escola um papel primordial na transmissão do conhecimento científico e cultural acumulado pela humanidade. Ao formular as bases teóricas da pedagogia históricocrítica, Saviani (1995, p. 17) analisou a função social da escola, assinalando que:

0 trabalho educativo é 0 ato de produzir, direta e intencionalmente, em cada indivíduo singular, a humanidade que é produzida histórica e coletivamente pelo conjunto dos homens. Assim, o objeto da educação diz respeito, de um lado, à identificação dos elementos culturais que precisam ser assimilados pelos indivíduos da espécie humana para que eles se tornem humanos e, de outro lado e concomitantemente, à descoberta das formas mais adequadas para atingir esse objetivo.

Não é nosso objetivo desenvolver as proposições de Saviani acerca da pedagogia histórico-crítica, mas tão somente reter a idéia de que cabe à escola o papel de transmissão do conhecimento produzido e acumulado socialmente pela humanidade. Pretendemos neste item relacionar essa idéia com algumas questões concernentes à formação do professor e ao ensino de sociologia no nível médio que vêm sendo problematizadas ao longo do curso.

A questão central que pretendemos trazer à reflexão pode ser resumida da seguinte maneira: frente à predominância na pesquisa educacional de concepções que negam 0 ato de ensinar como transmissão do conhecimento científico e cultural sistematizado, a Sociologia não estaria perdendo sua natureza científica, para se aproximar de uma prática pedagógica pautada unicamente na experiência imediata dos alunos?

Antes de avançarmos nossos argumentos, convém explicitar de forma breve esse debate. Para isso, vamos nos apoiar nas contribuições de Duarte (2003). Este autor parte justamente das concepções de Saviani a respeito da função social da escola para questionar algumas teses predominantes hoje nas pesquisas sobre a formação do professor.

Supondo haver a necessidade de repensar os fundamentos da profissionalização docente, tais teses sugerem retomar esse debate tendo em vista a elaboração de uma "epistemologia da prática", que se fundamentaria principalmente no conjunto de saberes que o professor tende a mobilizar em sua prática pedagógica cotidiana, em especial os saberes de sua própria experiência. Esta tese é formulada por Tardif (2000, p.12) que ao questionar as formas inadequadas com que os cursos universitários têm formado seus professores, resume assim seus argumentos: 
Do ponto de vista metodológico, essa definição exige o que poderíamos chamar de um distanciamento etnográfico em relação aos conhecimentos universitários. Dizendo de maneira polêmica, se os pesquisadores universitários querem estudar os saberes profissionais da área de ensino, devem sair de seus laboratórios, sair de seus gabinetes na universidade, largar seus computadores, largar seus livros e os livros escritos por seus colegas que definem a natureza do ensino, os grandes valores educativos ou as leis da aprendizagem, e ir diretamente aos lugares onde os profissionais do ensino trabalham, para ver como eles pensam e falam, como trabalham na sala de aula, como transformam programas escolares para torná-los efetivos, como interagem com os pais dos alunos, com seus colegas, etc.

As concepções apresentadas por Tardif são compartilhadas por Schön (1997) para quem a "reflexão-na-ação" deveria situar-se no centro das questões referentes à formação do professor por corresponder ao conhecimento tácito ou espontâneo que o professor detém em sua prática pedagógica cotidiana.

Inúmeras são as conseqüências dessas concepções quando se pensa nas diferentes dimensões do processo educacional. Seja nas questões ligadas à formação dos agentes educacionais, às questões relacionadas ao ensino e à aprendizagem, ou às questões próprias do currículo, as proposições mencionadas querem supor o desenvolvimento dos processos educacionais impulsionados fundamentalmente pela experiência imediata ou pela prática cotidiana de seus agentes.

Em sua análise, Duarte alerta para o retrocesso dessas concepções no que diz respeito à função primordial da escola que deveria se pautar pela garantia da transmissão do conhecimento sistematizado. Isto porque, de acordo com o autor o âmago dessas concepções reside justamente na distinção entre o conhecimento tácito (ou reflexão na ação) e o conhecimento escolar.

Essa distinção corresponderia, no plano epistemológico e pedagógico, à renúncia da função social da escola. Segundo Duarte (2003, p. 602), as teses apresentadas por esses autores que culminariam na proposição de Schön a respeito do professor reflexivo, " [...] desvaloriza [m] o conhecimento teórico/científico/acadêmico".

Esse movimento foi identificado por Moraes (2001 apud DUARTE, 2003, p.606) como o de um "recuo da teoria". Segundo a autora,

A celebração do 'fim da teoria' - movimento que prioriza a eficiência e a construção de um terreno consensual que toma por base a experiência imediata ou o conceito corrente de 'prática reflexiva' - se faz acompanhar da promessa de uma utopia alimentada por um indigesto pragmatismo [...]. Em tal utopia pragmatista, basta 0 'saber fazer' e a teoria é considerada perda de tempo ou especulação metafísica e, quando não, restrita a uma oratória persuasiva e fragmentária, presa à sua própria estrutura discursiva. 
Entendemos que as considerações de Duarte devem ser examinadas muito seriamente, sobretudo nesse momento em que sabemos que a pesquisa educacional, em particular as pesquisas sobre a formação do professor vêm sendo desenvolvidas a partir do referencial teórico de autores que preconizam o conhecimento tácito e todas as suas implicações nos processos educacionais, em detrimento do conhecimento escolar, pautado no acervo cultural e científico construído socialmente e acumulado pela humanidade.

Esta é a razão pela qual, retomando a questão que anunciamos no início deste item, achamos importante relacionar esse debate com algumas questões concernentes ao ensino de Sociologia para os alunos das escolas de nível médio.

Como se sabe, écorrente a afirmação de queénecessário aproximar-se do cotidiano dos alunos para trabalhar com a Sociologia. Muitas são as justificativas: a própria resistência dos alunos à disciplina é uma delas, mas também as dificuldades que os jovens alunos teriam em assimilar os conceitos sociológicos são aspectos freqüentemente lembrados pelos professores. Diante desta realidade, muitas são as estratégias utilizadas, mas todas têm em comum o esforço de aproximaç̧ão com o cotidiano dos alunos.

Sem pretender aprofundar essa questão que mereceria uma análise mais apurada, épreciso deixar claro que não estamos nos contrapondo à idéia de articulação dos conteúdos da Sociologia com o cotidiano dos alunos. Ao contrário, nosso entendimento é o de que essa articulação deve ocorrer não somente com a Sociologia, mas com todas as disciplinas. Aesse respeito podemos afirmar inclusive, que de um modo geral a escolaéhoje tributária de uma perspectiva teoricista e elitista do ensino, na medida em que nega os vínculos entre a elaboração teórica e a prática social.

Por prática social entendemos o processo através do qual o indivíduo se apropria da humanidade produzida histórica e coletivamente. Não se trata, portanto do indivíduo singular, mas das práticas sociais que são produzidas pelos indivíduos em suas relações sociais. Esse entendimento afasta a idéia do processo educativo limitado à interação de elementos subjetivos e individuaise reafirma a idéia de que o processo educativo deve ocorrer por meio da transmissão de um saber objetivo socialmente construído (DUARTE, 1998).

No tocante à problemática aqui apresentada, queremos ressaltar a distinção entre o que seria o trabalho educativo voltado para a experiência imediata ou empírica do indivíduo - que corresponderia ao conhecimento tácito, e o trabalho educativo voltado para a produção de indivíduos inseridos numa prática social que forma 0 acervo cultural e científico produzido e acumulado historicamente pela humanidade - que corresponderia ao conhecimento escolar.

Do ponto de vista sociológico, o ensino referendado unicamente no indivíduo singular impede, ao nosso ver a superação do senso comum, na medida em que permanece nos limites da experiência empírica ou imediata desse indivíduo. Por conseguinte, não fornece os elementos teóricos necessários para que o aluno adquira por meio dos conceitos 
sociológicos, a capacidade de desnaturalizar e de estranhar os fenômenos sociais, compreendendo-os não como práticas individuais, mas sim como relações sociais entre grupos e classes sociais.

Sabemos que esse processo não é simples, principalmente se levarmos em conta as especificidades da disciplina Sociologia no ensino médio que, como já mencionado ainda não tem um campo consolidado de estudos e pesquisas sobre conteúdos, metodologias e materiais didáticos adequados aos jovens do ensino médio. Entretanto, achamos que um princípio do qual não podemos abrir mão nessa empreitadaé o de que a Sociologia pode se constituir numa importante ferramenta de análise científica e de compreensão dos fenômenos sociais pelos alunos das escolas de ensino médio.

\section{ConsideraÇões FINAIS}

As considerações feitas neste artigo tiveram como objetivo central contribuir com o debate sobre o ensino da Sociologia para os alunos das escolas de nível médio. Do ponto de vista do conteúdo programático do curso de Didática Especial e Prática de Ensino de Ciências Sociais, nossa experiência tem-se revelado produtiva no propósito de conjugar as dimensões teórica e prática das questões relacionadas à formação inicial do professor e ao ensino de Sociologia, estimulando-nos a seguir nesta direção. Acreditamos inclusive que os problemas aqui levantados são resultado desse esforço de reflexão e de análise e, exatamente por isso, carecem de aprofundamento.

\section{REFERÊNCIAS}

BOURDIEU, Pierre. A juventude é apenas uma palavra. In: Rio de Janeiro: Marco Zero, 1983.

Questões de Sociologia.

BRASIL. Ministério da Educação. SEMTEC. Parâmetros Curriculares Nacionais para 0 ensino médio. Área Ciências humanas e suas tecnologias. Brasília, 1999.

CANDAU, Vera Maria (Org.). Rumo a uma nova didática. Petrópolis: Vozes, 2003.

CENTRAL DE ESTÁGIO. Projeto. Faculdade de Educação da UFRJ e Escolas de Educação Básica: Relações Institucionais. Rio de Janeiro: UFRJ/FE, 2004. (mimeo).

DA MATTA, Roberto. 0 ofício de etnólogo, ou como ter "anthropological blues". In: NUNES, Edson de Oliveira (org). A aventura sociológica: objetividade, paixão, improviso e método na pesquisa social. Rio de Janeiro: Zahar Editores, 1978. p. 23-35.

DAUSTER, Tânia. Construindo pontes: a prática etnográfica e o campo da educação. In: DAYRELL, Juarez (Org.). Múltiplos olhares sobre educação e cultura. Belo Horizonte: UFMG, 1996. p. 65-72. 
DAYRELL, Juarez. A escola como espaço sócio-cultural. In: DAYRELL, Juarez (Org.). Múltiplos olhares sobre educação e cultura. Belo Horizonte: UFMG, 1996. p. 65-72.

DUARTE, Newton. Concepções afirmativas e negativas sobre o ato de ensinar. Cadernos CEDES, Campinas, v. 44, 1998.

. Conhecimento tácito e conhecimento escolar na formação do professor (por que Donald Schön não entendeu Luria). Educação e Sociedade, Campinas, v. 24, n. 83, 2003.

GEERTZ, Clifford. El antropólogo como autor. Barcelona: Paidós, 1989.

LOPES, Alice Casimiro. Organização do conhecimento escolar: analisando a disciplinaridade e a integração. In: CANDAU, Vera Maria (Org.). Linguagens, espaços e tempos no ensinar e aprender. Rio de Janeiro: DP\&A, 2000. p. 147-164.

MALINOWSKI, Bronislaw. Introdução. Tema, método e objetivo desta pesquisa. In:

Os argonautas do pacífico ocidental. São Paulo, Abril Cultural, 1978. p. 17-34. (Coleção 0s Pensadores).

MONTEIR0, Ana Maria. A prática de ensino e a produção de saberes na escola. In: CANDAU, Vera Maria (Org.). Didática, currículo e sabres escolares. Rio de janeiro: DP\&A, 2002. p.129-148.

SAES, Décio Azevedo Marques de; ALVES, Maria Leila. 0 conflito social na escola pública (uma abordagem sociológica). SIMPÓSIO BRASILEIRO DE POLÍTICA E ADMINISTRAÇÃ̃, 21., CONGRESSO LUSO-BRASILEIRO DE POLÍTICA E ADMINISTRAÇÃO DA EDUCAÇÃO, 3., Espaço Público e Gestão da educação: desafios de um novo tempo, Recife, 2003. Anais ... Recife, 2003.

Problemas vividos pela escola pública: do conflito social aos conflitos funcionais (uma abordagem sociológica). Linhas Críticas, Brasília, v. 10, n. 19, 2004.

SAVIANI, Dermeval. Pedagogia histórico-crítica: primeiras aproximações. São Paulo: Autores Associados, 1995.

SCHÖN, Donald. Formar professores como profissionais reflexivos. In: NÓVOA, Antonio (Org.). Os professores e a sua formação. Lisboa: Dom Quixote, 1997.

TARDIF, Maurice. Saberes profissionais dos professores e conhecimentos universitários: elementos para uma epistemologia da prática profissional dos professores e suas conseqüências. Revista Brasileira de Educação, n. 13, 2000.

TURNER, Victor. O processo ritual: estrutura e anti-estrutura. Petrópolis: Vozes, 1974.

VELHO, Gilberto. Observando o familiar. In: . Individualismo e cultura. Rio de Janeiro: Jorge Zahar Editor, 1994. p. 121-132. 